\title{
Defensa de la poli(é)tica
}

\author{
PABLO RÓDENAS UTRAY \\ Universidad de La Laguna, Tenerife
}

RESUMEN. El generalizado y creciente malestar con los modos estándar del hacer político a escala mundial plantea un reto inexcusable al filosofar del presente: someter la política misma a revisión crítica. Reconocer que la filosofía política sólo puede refundarse partiendo de su autocrítica radical conlleva, a su vez, que se deshaga de la matriz sobre la que se levanta la política realmente existente, que es una matriz belicista basada en la distinción amigo/enemigo y sus derivados. E implica, además, que se reconozca la necesidad de reconstruir conceptualmente la relación existente en los mundos de la vida de la modernidad entre acción política y actitud ética, entre posición política y disposición moral. En este contexto teórico-programático, el artículo informa de cómo surgió hace años la conveniencia de introducir la categoría de «poli(é)tica» en el discurso filosófico-político, para marcar así esa estricta tarea reconstructiva que va desde una filosofía crítica de la política a una filosofia política de la legitimidad constituida por los imperativos de disidencia y resistencia ante el mal social y la dominación. Sin embargo, dado que recientemente han surgido algunos usos de la categoría de poli(é)tica que la distorsionan en el fondo y en la forma, el artículo defiende la propuesta poli(é)tica originaria desmarcándose previamente y de forma razonada de esas distorsiones.
ABSTRACT, The local and global standard ways of getting involved in politics have led to a growing and widespread sense of unease which has given rise to an unavoidable challenge to the current philosophycal activity; Politics itself must be subjected to a critical revision. If it is admitted that the Political Philosophy can only be refounded starting from its own radical self-criticism, it is also necessary to take it out from the matrix on which the real present politics has been set up, a militaristic base founded on the uneven distinction between friend/enemy and some others. Furthemore, it entails to recognise the need for a conceptual rebuilding of the relationship between a political action and an ethical attitude, between a political position and a moral disposition in the world of life of the modernity. It is in this theoretical and programmatic context where the article informs about how it became advisable to introduce the category of «poli(e)thics» in the philosophical-political discourse some years ago, in order to highlight that strict and reconstructive task which involves not only a Critical Philosophy of Politics but also a Political Philosophy of Legitimity made up of the ethical imperative of dissent and the poli(e)thical imperative of resistance to social evil and domination. Nevertheless, as it has recently come up some uses of the category of poli(e)thics which distort its meaning and its form, the article supports the original proposal of poli(e)thics although it previously gives arguments to dissociate itself from those distortions. 
Cuando Cervantes reaccionó ante el Quijote de Avellaneda con más melancolía que enojo, nos legó un imperecedero ejemplo de lo que, más allá de aquel desaguisado, significa adoptar una actitud razonable. En esta nota me propongo, a la modesta escala que me corresponde, aplicarme al pie de la letra esa tempranomoderna lección cervantina. Acepto así con gusto la invitación que me hace Isegoría a que exponga mi vieja propuesta de entender la relación de la política con la ética a partir de la categoría de «poli(é)tica». Como he defendido esa categoría a lo largo de más de una década, el lector me perdonará si de entrada le confieso que cada vez que me han llegado noticias de su adopción, o mención en un sentido similar al propuesto, me he llevado una pequeña alegría. Sin embargo, ¿qué debo pensar ahora, cuando veo que empiezan a aparecer utilizaciones del término que lo distorsionan no sólo en su grafía, quitándole el necesario paréntesis, sino también en su significación, omitiendo su origen conceptual y sus fuentes? Tal vez haya llegado el momento - me digo- de que grite para mis adentros «iCervantes!» y recuerde que ya había previsto que sería inevitable que algo así ocurriese. Y puede que incluso hasta sea conveniente, si de esta manera se puede contribuir a que prosiga el debate sobre el papel de la ética en la política.

Tomo pie en lo dicho para exponer en positivo el porqué de mi brega por una filosofia poli(é)tica que se autocomprenda, primero, como filosofía crítica de la politica y, luego, como filosofía política de la legitimidad. No en vano durante los últimos veinte años he nucleado una buena parte de mi labor crítica y reconstructiva de la idea estándar de política alrededor de su relación con la ética, y desde hace más de diez años de forma explícita alrededor de la categoría de «poli(é)tica». Esta categoría - la señal o marca que expresa mi tematización de esa relación- es además el elemento central de un libro en el que aún trabajo, concebido y diseñado para recoger esa labor, que llevará por título Poli(é)tica (Tentativa de una filosofía crítica de la política) ' y que anuncio justo como aviso para navegantes ${ }^{2}$.

Sin embargo, admito a la par que $\mathrm{mi}$ uso en sentido estricto del término poli(é)tica no niega la posibilidad de otros usos, diferentes e incluso contrapuestos al mío; de algunos de los que ya tengo referencia discutiré a continuación, primero, desde el punto de vista de la forma y, luego, del fondo. Porque, en sentido amplio, lo que la voz poli(é)tica subraya es el hecho genérico de que todas las políticas, tanto las que apoyamos como las que rechazamos, incorporan morales particulares, aun cuando lo desconozcan o lo contradigan, morales que forman parte de su núcleo ético. En este sentido, la palabra poli(é)tica explicita en todo momento un supuesto de entrada: el cuestionamiento de la posibilidad tanto de separar de forma absoluta las políticas de las éticas como de identificarlas, ya sea porque se defiende una concepción «realista» de la política o una «idealista» de la ética.

\section{I}

En su doble sentido pues, amplio y estricto, mi uso de un palabro como poli(é)tica no es el resultado de una improvisación, sino más bien el producto de una decisión largamente meditada, y luego una y otra vez ratificada ${ }^{3}$. Todos los que hemos reflexionado sobre la relación de lo ético y lo político sabemos de la dificultad expresiva que conlleva comunicar y hacer comprensible nuestra reflexión. Como es fácil suponer, el anómalo paréntesis intercalado no es algo gratuito, sino del todo necesario. Y necesario antes que nada para evidenciar en todo momento esa anomalía o dificultad expresiva ineliminable que conlleva siempre la tensa relación de lo político con lo ético. 
No obstante, recientemente se ha empezado a utilizar una variante de la palabra poli(é)tica sin remilgos de ninguna clase. Así, el nuevo término «poliética» surge, una de dos, o componiéndolo directamente a partir del prefijo «poli» y la palabra «ética», o retirándole el paréntesis al de poli(é)tica. Ahora bien, tanto en un caso como en el otro, sus usuarios habrán de admitir que escrita de esa manera la palabra pierde toda referencia a la política, tal como sucede con términos de similar construcción: por ejemplo, «policlínica», que designa un establecimiento con diferentes especialidades médicas, o «polisemia», que define un signo o conjunto de signos con varios significados. El vocablo poliética parece entonces que se refiere a algo similar a una ética de la diversidad o a una ética pluralista, ajena en cualquier caso - al menos de forma explícita - a la política. De ahí que, por mi parte, haya tenido que ir más allá de esa mera ocurrencia, a buen seguro bastante frecuente y nada original, introduciendo el paréntesis de marras ${ }^{4}$.

De esa manera, poli(é)tica es el vocablo que resulta de la incrustación de la voz «ética» en la voz «política», política que es tanto el punto de partida explícito como el punto de llegada evidente del proceso conceptual que estoy describiendo. Puesto que de la acción política - junto a la ideología, la ciencia y la filosofía política - es de lo que aquí abiertamente se trata. Pero de tal modo que en el nuevo término, gracias a la introducción del paréntesis con la letra «e», se hace del todo visible y obligada una significación polivalente - en la escritura primero, para después desde ahí exportarla a la fonética - que alude a la política al tiempo que a la ética que toda política conlleva. Que es también de lo que se trata ${ }^{5}$.

Sin embargo, el asunto es más complejo. Porque puede que la idea de introducir ahora el término poliética tenga algo que ver con las viejas tentaciones de atajo sim- plificador, es decir, con la tentación de reivindicar que la política nada tenga que ver con la ética o, en sentido contrario, pretender que la política no es más que ética a secas. Se trata de concepciones ético-políticas harto conocidas en la historia del pensamiento y - a mi juicio- concepciones ciertamente objetables. Antes que plantear el problema, de un plumazo se lo niega. Por ejemplo, en formulación actual, una acepción de poliética consiste en postular la admisión de la diversidad o pluralidad de las éticas. Otra estriba en propugnar la necesidad de identificar o fusionar ética y política. Y una tercera, en sostener ambas ideas entrelazadas. Quizá merezca la pena detenerse por un instante en el examen de las tres, dado que su debilidad es, a mi juicio, palmaria.

La primera acepción del término poliética es la que se centra en la necesidad de admitir la diversidad o pluralidad de éticas. A poco que nos fijemos en ella, revela de inmediato que nada tiene que ver con la adscripción a una ética pluralista o ética de la diversidad (a la que algunos autores preferirían llamar ética pública), tal como en principio parecía anunciar la composición del sufijo «poli» con la voz «ética», situándose al margen de cualquier referencia a la política. Porque si la idea de pluralidad o diversidad de éticas se concibe como un mero juicio de hecho sobre algo que se da por supuesto en una época dada, como una afirmación no normativa de obligada admisión ${ }^{6}$, se nos está pidiendo que admitamos todas y cada una de las morales de hecho existentes en esa situación, aunque sean incompatibles entre sí e irrazonables ${ }^{7}$. Hay ahí un sesgo relativista innegable. Pero si no se dice nada más al respecto, prefiero abstenerme de introducir nuevos argumentos sobre las diferencias entre el relativismo cultural y el relativismo ético.

Por otro lado, la segunda acepción del término poliética, esto es, la que propugna que hay que admitir como necesaria la 
identificación o fusión de ética y política, se presenta impregnada de un innegable aroma fundamentalista. Y ello debido a que, en su exceso normativo, esta acepción renuncia a la ineludible exploración del campo minado de las relaciones de lo ético y lo político realmente existente. ¿Qué ética -y cómo- sería la que se fusionase con la política? ¿Todas las de la pluralidad juntas o cada una de ellas? $\measuredangle \mathrm{Y}$ con qué política - y cómo - se daría la fusión, dado que la pluralidad de políticas no parece menor que la de éticas? Sólo un cierto aliento fundamentalista, contradictorio con la necesidad de admitir la pluralidad de éticas (acepción primera), puede inducir (sic) a admitir la necesidad de fusionar ética y política (acepción segunda). Precisamente por ello la genealogía de esa fusión - démosle ya su nombre: confusión - no proviene de la primera acepción, sino de dos ideas premodernas en las que se apoya, la que señala, de una parte, que todo es política, y la que proclama, de otra, que toda política es ética colectiva ${ }^{8}$

Por último, sostener como tercera acepción de poliética el entrelazamiento de las dos anteriores equivale a pretender que esa identificación o fusión entre lo ético y lo político como necesaria a la vez que como normativa surge como aspiración de los tiempos y en los tiempos de la diversidad o pluralidad de éticas ${ }^{9}$. Así, ese supuesto deseo epocal de recuperar el todo perdido (fusionado e idéntico) arranca del rechazo de la irreversible diferenciación de ética y política como esferas de valor autónomas en la modernidad. Se estaría recurriendo de esta forma a una fundamentación historicista, en la que el relativismo de partida se dobla de manera incongruente de fundamentalismo. En fin, ante semejante conjunto de abruptas pretensiones -en las que, a mi juicio, se confunde lo contingente con lo necesario y lo fáctico con lo posible ${ }^{10}$, y en las que se olvida aquel viejo dictum sacristaniano que decía que, en filosofía, el matiz es concepto- quizá es preferible echar mano de la prudencia cervantina, o incluso de la aristotélica - pues, al fin y al cabo, ésta fue uno de los primeros intentos de tender un puente desde las virtudes dianoéticas hacia las virtudes éticas - y guardar silencio sobre esos incipientes y erráticos usos de un término como «poliética», tan sorprendente como podrían serlo, por ejemplo, «poliderecho»y «polijusticia».

\section{II}

En cualquier caso, espero que llegados a este punto, se comprendan mejor las razones del desaliento que le lleva a uno a preguntarse si todavía tendrán remedio, aunque sea a largo plazo, los estropicios que amenazan al uso, por abuso, de nuestra palabreja originaria. Pese a lo cual, entre la melancolía por la faena y el entusiasmo por la tarea, me propongo no claudicar en esta empresa vital a la que llamé poli(é)tica, aunque con más escepticismo aún del que por cuestión de temperamento acostumbraba.

La palabra poli(é)tica ya no es una rareza ortográfica ni fonética en mis diferentes entornos laborales, por no hablar del círculo de mis amistades. Por eso sugerí al inicio que era algo así como la denominación de origen de una filosofía crítica de la política. La crítica de esa cosa a la que llamamos «política» resulta obligada para cualquier filosofar que se adjetive como "político» y se precie de serlo, pues, a mi juicio, la aceptación acrítica de la política, tal como es ${ }^{11}$, invalida de entrada todo filosofar a ese respecto. $\mathrm{He}$ insistido con reiteración, tal vez no exenta de cabezonería, que no cabe ninguna filosofía política realmente valiosa que no haya de partir del ejercicio de la razón crítica-y-autocrítica aplicada a la propia política ${ }^{12}$. No en vano se trata de la actividad pública más presente en la comunicación actual a la vez que la que menos cre- 
dibilidad tiene. La misma expresión «filosofía política» es ya de por sí una petición de principio. Una petición que no se puede conceder por las buenas, puesto que encubre un supuesto de congruencia entre sus términos que tal vez nunca - o quizá sólo de forma excepcional- se haya dado. Designa ante todo el nicho de un problema intelectual, además de referirse al habitáculo de una «disciplina» institucionalizada (que en la España contemporánea tiene - por cierto - menos de veinte años de historia). Ésta es la razón por la que mantengo que esta mal avenida pareja de hecho - que no matrimonio - debe seguir siendo lo que siempre ha sido, una indisciplina posible, en vez de una imposible disciplina ${ }^{13}$

Desde esta perspectiva, la filosofía política se preocupa de las relaciones entre el decir y el hacer humano genérico. Esto es, de tender puentes entre teoría y práctica. En términos más precisos, se ocupa de la racionalidad de lo que se puede denominar macroprogramas de ideología y praxis política; o, lo que es lo mismo, de las relaciones de congruencia o incongruencia entre los dos tipos básicos de programas que se articulan tras toda acción política concreta ${ }^{14}$. Ahora bien, ¿es posible defender hoy una idea de racionalidad política (es decir, de racionalidad poli(é)tica) que no se reduzca a razón instrumental, ni a razón cínica? El interrogante muy pocas veces se ha abierto de forma explícita. Fundamentalmente a causa de que casi siempre hay una previa respuesta negativa, que es el obstáculo que dificulta la formulación de la pregunta ${ }^{15}$ Pero quienes se mantienen erre que erre en esta respuesta negativa habrían de saber que tienden a la demonización metafísica de toda política (he llamado en algún momento a esta concepción tesis de la insuperabilidad de la politica existente, $\mathrm{y}$ he sostenido que sólo puede ser defendida desde una filosofía de la historia quietista). Concebida, pues, en términos rela- cionales, la filosofía poli(é)tica es - como digo - interpretación argumentada crítica $y$ reconstructiva. $\mathrm{Y}$ en su equilibrio reflexivo otorga primacía a la crítica, en aras de la continua señalización de los límites irrebasables que debe reconocer toda reconstrucción, en su frágil provisionalidad.

Centrada, entonces, la crítica en el análisis interno y externo de la acción política pública, discursiva y/o realizativa, la reflexión se centra en los dos grandes parámetros que la envuelven: en la exploración de lo nuevo de la situación epocal en la que ha de desarrollarse la propia filosofía poli(é)tica del presente, y en la búsqueda de la matriz histórica y conceptual que caracteriza a la concepción estándar de la política moderna y tardomoderna.

Respecto a lo primero, recordaré - ante la chata crítica conservadora, desde hace mucho en ascenso- que tanto la mía como otras filosofías poli(é)ticas de corte igualmente razonable han tenido en la última década que pensar de forma directa el lineamiento que sobredetermina a cualquier otro de los que han de ser tenidos en cuenta (ya sea tecnológico, económico, etc.) en las sociedades de este principio del siglo XXI largo (siglo que - a mi juicio y contra la cronología estándar - empezó en los noventa). Me estoy refiriendo al mal social, pensado de manera no metafísica, que se concreta en la aparición de una nueva violencia belicista, para mayor desgracia en constante incremento e impunidad ${ }^{16}$. La primera tarea en la agenda de la filosofía poli(é)tica, su punto de partida - como llevo planteado desde los primeros noventa, ante la mirada displicente de parte del establecimiento académico, mirada que se hizo trágica a partir del 11 de septiembre de 2001 - sería pensar el belicismo de nuevo tipo que empezó a ensayarse en todos los espacios vitales (desde las guerras de los hogares a las guerras de las estrellas, pasando por todas las demás) a partir de 1991. Y junto a éste, 
los burdos procesos de legitimación mediática que lo vienen acompañando, levantados todos desde los paradigmas realista, moralista y legalista de las relaciones internacionales.

El segundo parámetro al que he aludido, a saber, la búsqueda crítica de la matriz histórica y conceptual de la acción política moderna, tal como ésta se presenta en sus concepciones «sintéticas» o «comprehensivas», se justifica en que es la vía más apropiada para la reconstrucción de la matriz de una concepción «analítica» o «política» en sentido estricto. Esto es, la concepción que explicite los principales componentes de la acción política y oriente el diseño discursivo de una alternativa, la acción poli(é)tica ${ }^{17}$, como acción específica que tenga sus bases en la razonabilidad pluralista de los individuos que se comprometen con una convivencia incluyente y equitativa en los plurales mundos de la tardomodernidad presente, la de las actuales sociedades informacionales del espectáculo. Por eso, de cara a su crítica, la reconstrucción del modelo histórico-conceptual de la política estándar de la modernidad es fundamental. A partir de ahí, es posible reconstruir y comprender el contramodelo juridicista de sobredeterminación de la política que históricamente realizó el liberalismo. Un contramodelo que evidencia, por un lado, el carácter revolucionario en origen - a veces olvidado- de su concepción de la política y, por otro, los límites mismos de esta concepción, ejemplificados en el estado mínimo de derecho edificado sobre el imperio de la ley. Al tiempo, creo que sólo esa reconstrucción interpretativa es la que puede dar pie a su reformulación éticopolítica, ahora ya desde una perspectiva equitativista, transliberal (más que ultraliberal o postliberal) si se quiere y no conservadora. Éste sería el contramodelo poli(e)ticista.

Esta analítica crítico-reconstructiva, además, se apoya en la distinción catego- rial entre la política, lo político y el político en sentido estricto, como trasuntos a su vez de categorías como las de acción, relación y sujeto ${ }^{18}$. Ahora bien, la crítica y reconstrucción de la política (considerada de nuevo en el sentido amplio e inclusivo de estas tres categorías) no puede siquiera ser formulada si previamente no se reconoce la existencia de un problema muy especial, el del papel que juega la ética en la política, o -dicho en términos más precisos - el problema de la relación que de hecho hay y el problema que de derecho debiera haber entre las actitudes éticas y las acciones políticas que nos constituyen y definen ${ }^{19}$. Mi educación familiar (vinculada en la distancia a ciertas huellas liberales dejadas por la Institución Libre de Enseñanza en la posguerra), y mi politizada juventud (ligada a un existencialismo de corte vitalista al que luego incorporé no sin dificultad un marxismo cada vez más heterodoxo), amalgamado todo ello en un compromiso político-práctico tan intenso como extenso (de más de un cuarto de siglo de duración y que incluyó la última década de la dictadura), me permitió vivir a fondo y de cerca las interioridades de la política, «descubriendo» que todas las posiciones políticas implican, se quiera o no, el recurso obligado a dis-posiciones morales, disposiciones que suelen ser diferentes y, muchas veces incluso, opuestas y enfrentadas (según sean los talantes y la razonabilidad de los individuos en cada situación) ${ }^{20}$.

En fin, mientras la pasión política hace sospechosa para algunos mi dedicación académica, la convicción moral hace para otros irritante mi compromiso político. Sin embargo, es de esta manera como surge -enlazando ambos extremos en una simultaneidad perseverante y contraria a las ortodoxias académica y política- este embrión de crítica de la política desde la política, por decirlo con uno de los lemas que orienta mi reflexión filosófica. Desandando de modo genealógico la 
senda que históricamente va desde la moralidad kantiana a la historicidad marxiana y que pasa por la politicidad hegeliana, o que va desde el mismo arranque a la transvaloración nietzscheana y que pasa por la voluntad schopenhaueriana, creo que es posible reinterpretar de modo no formalista ni cognitivista los imperativos ínsitos en las lides poli(é)ticas ${ }^{21}$. Al mismo tiempo, tengo la convicción de que es del todo necesario resituar el problema de la justicia en el núcleo mismo del filosofar poli(é)tico, concretándola de modo sustantivo en la legitimidad ético-política y diferenciando ésta de la legitimación socio-política ${ }^{22}$.

El imperativo ético de disenso y el imperativo poli(é)tico de resistencia se convierten así en concreciones del principio de ilegitimidad de toda dominación humana. De ahí que decir poli(é)tica como filosofía crítica de la política sea equivalente a decir poli(é)tica en tanto que filosofia política de la legitimidad, tal y como sugerí al inicio. Esto es, como filosofar político deslegitimador de todo poder de dominación, filosofar que se opone de modo crítico a las diferentes filosofías políticas legitimadoras del statu quo, lo mismo si son de raigambre liberal-conservador como social-liberal, y no digamos ya si se trata de filosofías deslegitimadoras de contenidos antidemocráticos reaccionaristas o revolucionaristas ${ }^{23}$. Porque, a fin de cuentas, la viabilidad de una vida buena en una sociedad de bienestar no puede ser en absoluto ajena a la construcción de órdenes políticos democráticos y pluralistas, en los que el conflicto ciudadano se aborde desde procesos, estructuras y culturas de contención legítima de la violencia. Es decir, desde actitudes y acciones civilizatorias, razonables e igualitaristas. El tránsito de la política a la poli(é)tica no pasa, pues, en conciso resumen, por los vertiginosos atajos de ninguna poliética.

Termino, pues, volviendo al principio. El único interés que me asiste en esta melancólica defensa es el teórico-práctico, no desde luego el del enojo y la querella. Sin despreciar para nada los esfuerzos del pasado reciente por impulsar el debate pluralista, tal vez la filosofía moral y política de las hispanidades de uno y otro lado del Atlántico debería entrar en una nueva fase, más abierta y autocrítica, en la que todos cuantos lo deseen puedan deliberar amistosamente, reconociéndose y reconociendo a los demás como interlocutores de pleno derecho. Los que gustamos de circular por vías periféricas, aun con el riesgo de que de vez en cuando seamos arrojados a la cuneta, nos contentamos simplemente con eso.

\footnotetext{
1 Advierto al lector de que en algunas de las notas que siguen me veré obligado - no sin incomodidada hacer referencia a trabajos míos de los últimos años. Poli(é)tica es una obra anunciada, desde 1991, con el título provisional de Filosofia de la politica y, desde 2000, con el de Ensayos de poli(é)tica (Tentativa de una filosofia crítica de la política). Metido ya en este trajín, apuro la ocasión para reiterar que también están anunciados los libros Necesidad de comprender (Cartas poli(é)ticas de disenso), y el que le ha de suceder Libertad de actuar (Avisos poli(é)ticos de disenso).

${ }^{2}$ Es legítimo que el lector de talante resuelto se pregunte -como también me lo pregunto yo- por
}

las razones de que esa obra no haya sido aún publicada. Mi respuesta, lejos de demorarse en excusas contextuales, sólo puede apuntar a la asunción completa de toda la responsabilidad por mi parte. Si unos avanzan demasiado deprisa, otros avanzamos demasiado despacio, contra lo que parece el signo de los tiempos. Como diría Pessoa: «No trabajamos bastante y simulamos trabajar demasiado, vamos muy rápido de un lugar donde no se hace nada a otro donde no hay nada que hacer; es lo que llamamos el ritmo febril de la vida modernas.

${ }^{3}$ Desde 1993 la palabra poli(é)tica está conceptualizada no sólo en algunos de mis artículos, sino que 
aparece también en bastantes de sus títulos. He aquí una relación: «Poli(é)tica (Fundamentos para una alternativa antifundamentalista)», Página Abierta, 26, 1993; «El segundo imperativo poli(é)tico o imperativo de resistencia», Disenso, 4, 1993; «Poli(é)tica, o el tránsito del interés a la legitimidad», Laguna. Revista de Filosofia, 2, 1994; «Hacia una teoría poli(é)tica de la democracia», Disenso, 15, 1996; «La política como guerra (Una crítica poli(é)tica)», Laguna, 5, 1998; «Políticos, intelectuales y ciudadanos (Una vindicación del sujeto poli(é)tico en comunípolis)», Laguna núm. extraordinario, 1999; «La sociedad informacional del espectáculo (Una aproximación poli(e)tica)», Laguna, 7, 2000; «El rechazo del nuevo paradigma por razones poli(é)ticas», Cambio de paradigma en Filosofía Política, Cuaderno 7, Seminario Público Fundación Juan March, 2001.

${ }^{4}$ En el primero de los artículos recién citados (también publicado en Disenso) hice referencia a cómo surgió a finales de 1992 el término en la redacción de esa revista, historia sentimental que contaré con más detalle en Poli(é)tica.

5 Asimismo, en ocasiones, rizando el rizo si se quiere, he llegado a decir que, de forma secundaria e implícita, la «e» incrustada podría considerarse que alude incluso a los aspectos e-motivos y e-quitativos, por un lado, y e-pistémicos y e-xpresivos, por el otro, de toda política, en referencia esto último al grave problema, cada vez más acuciante, de la mentira, la desinformación y la manipulación en la política contemporánea.

${ }^{6}$ Conviene subrayar que el vocablo «admitir» es evaluativo e implica la aceptación o recepción voluntaria de un algo dado. Por tanto, la admisión por parte de un hablante de la diversidad o pluralidad de éticas no constituye más que una actitud evaluativa que se expresa en un juicio de valor que pretende pasar por juicio de hecho.

${ }^{7}$ Cabría pensar que lo que se admite es sólo el hecho político de que haya una diversidad de morales y el derecho jurídico a que en toda democracia las haya. Pero después de Auschwitz cabe preguntar, ¿en qué sentido la admisión de aquel hecho y de este derecho es también una exigencia ética de admisión de todas ( $y$, por tanto, de cada una de) esas morales? ¿No estaríamos ante alguna suerte de relativismo éti co, un relativismo ajeno por ejemplo al whecho del pluralismo razonable complejo» del que habla John Rawls?

${ }^{8} \mathrm{~A}$ mi juicio, la génesis actual de la identificación o fusión de ética y política a partir de esas otras dos ideas premodernas trae al recuerdo algunas de las lecturas más simplificadoras que se hicieron en el pasado de la Filosofia del derecho hegeliana.

${ }^{9}$ Obsérvese cómo en este punto crucial se incurre en los enredos de la falacia naturalista en su vertiente historicista. Pues si la necesidad de la fusión de lo ético y lo político se justifica en algo así como un deseo de tradición o innovación que naciese en la época moderna, se estaría afirmando que surge de la historia. Asi, la normatividad ético-política quedaría derivada de la necesidad histórica.

10 En este tercer sentido de poliética, la admisión de la diversidad o pluralidad de éticas no se compadece en nada - a mi juicio- con la necesidad de identificar o fundir ética y política, siendo además, el primer sentido, una innecesaria admision, que se adentra en el relativismo ético, $y$, el segundo, una inadmisible necesidad, que se engasta en el fundamentalismo moral. La descuidada defensa de juicios de valor inadvertidos, pensando que se trata tan sólo de juicios de hecho evidentes, facilita que se postulen pasos ilusorios, esos que intentan transitar desde supuestas descripciones de hechos-y-deseos históricos hasta prescripciones de principios-y-normas ético-políticas, creyendo que así se encuentran bien argumentadas y justificadas. Todo ello resulta como mínimo chirriante, por no decir que incongruente (como antídoto en estos menesteres siempre resulta recomendable la aplicación del super-principio de los pies de plomo filosóficos de Moulines, con el que se puede evitar incurrir, primero, en el «todo-gris» de la primera acepción $\mathrm{y}$, luego, en el «o-blanco-o-negro» de la segunda).

11 Por decirlo con palabras transcritas en su día por F. Savater, la política estándar realmente existente es percibida por muchos jôvenes como un rollo muy chungo, en el que no hay más que chorizos que mienten hasta cuando duermen, rollo que la gente corriente no puede hacer nada para cambiar porque siempre tienen la última palabra los cuatro enteraos que están arriba (en Política para Amador, p. 14).

12 Véase «Una definición de la política», Suplementos Anthropos, 28, 1991, pp. 71-80, y «Una definición de la filosofía política», Revista Internacional de Filosofia Politica, 1, 1993, pp. 53-69.

${ }^{13} \mathrm{Si}$ el filosofar político puede seguir siendo, como ha sido, una indisciplina posible se debe también a que la negación postmoderna de la política no fue, en absoluto, de obligado cumplimiento: la filosofía política tampoco puede ser, como es obvio, una imposible indisciplina (cf. «Una definición de la filosofía política», op. cit., pp. 55-57)

14 Ibid. Mi preferencia por el término «ideología», antes que por el de «teoría», para referirme al objeto discursivo de la política, puede parecer en primera instancia una elección ortodoxa, pero lo sería sólo si no hubiese tras ella una prolongada teorización del concepto de ideología, que arranca de la crítica de sus ortodoxas acepciones peyorativas y meliorativas (véase Ideologia e historicidad. Cuestiones fronterizas entre la racionalidad teórica y la racionalidad práctica, Universidad de La Laguna, 1987).

is En «Una definición de la política» (op.cit., p. 79) escribí a este respecto que la racionalidad política debería ser entendida como la capacidad (científi- 
ca, técnica, artística y ética) del tejer prácticas, voluntades y teorías en estrategias de acción con los materiales de la vida en sociedad (materiales fácticos, representacionales, valorativos y normativos).

${ }^{16}$ Véase «Repensar la guerra (Legitimidad y legitimación de las nuevas formas de violencia bélica)», en B. Riutort (ed.), Conflictos bélicos y nuevo orden mundial, Barcelona, Icaria, 2003.

${ }^{17}$ Cf. «Los límites de la política», en F. Queșada (ed.), Filosofia política I. Ideas y movimientos socia les, Madrid, EIAF 13, Trotta, 1997.

18 Sobre la política puede verse el citado «Una definición de la política»; sobre lo político: «Política con razonabilidad (una tentativa de reconstrucción programático-conceptual de lo razonable político)», en F. Quesada (edit.), Siglo xxI: ¿un nuevo paradig ma de la política?, Barcelona, Anthropos, 2004; sobre el político: «El ciudadano como sujeto de la política (En diálogo con Aranguren y Muguerza)», en F. Quesada (dir), Naturaleza y sentido de la ciuda danía hoy, Madrid, UNED Ediciones, 2002. En el segundo de los trabajos citados, la categoría de $l o$ político se construye valorativamente a partir de la teorización de la categoría husserliana de «mundo de la vida». Así, la problematización del mundo social de la vida sería la que da lugar atributivamente al mundo político de la vida. Pero para pensar éste se cuestionan dos obstáculos a los que llamo dogmas del racionalismo político, a saber, las distinciones público/privado y sociedad civil/sociedad política (véase también «Dos dogmas del racionalismo político», en D. García-Marzá y E. Glez. Esteban, Entre la ética y la política: éticas de la sociedad civil, Castelló de la Plana, Universitat Jaume 1, 2003). Por su parte, en el tercero de los trabajos citados, la categoría de el político se identifica de forma normativa con el ciudadano o individuo poli(é)tico, entendido como la categoría que agrupa a los preferidores razonables de voluntad autónoma.

19 Una nítida ilustración de relación congruente entre actitud ética libre y acción política responsable y de la primacía de la primera sobre la segunda en una situación en la que lo fáctico no cancela lo posible, analizada - además - al margen del curso pos terior de actitudes y acciones (por ejemplo, del ulterior apoyo a la resolución 1546 del Consejo de Seguridad), fue la ejemplar decisión de J. L. Rodrí guez Zapatero de retirar las tropas españolas de guerra de Irak nada más ser investido como presiden- te del gobierno de España, sorprendiendo a diestro y siniestro (empezando por la mayoría de sus correligionarios).

${ }^{20}$ Desde esta perspectiva, carece tanto de sentido la admisión de la pluralidad de éticas como la necesidad de la fusión de ética y política: el individuo político racional y emancipador - escribí en algún momento (véase «Una definición de la política», op. cit p. 79) - al reflexionar debe buscar congruencia entre lo que está pensando/diciendo y va a hacer; y al actuar debe ser congruente en la acción con lo que piensa/dice. Tiende así un puente interno entre lo que piensa/dice y lo que hace (conquista así su libertad subjetiva). Sin embargo, también debe tender un puente externo a él entre lo que hace y lo que hacen otros (se conquista así la libertad objetiva). La políti ca aparece aquí como lo que básicamente debería ser una interacción ideológico-comunicativa y una interacción práxico-realizativa de naturaleza racional y emancipatoria, que nada tiene que ver con la idea recogida por Savater (supra nota 11 ).

2. A este respecto, reconozco con gusto una vez más que sólo pude recorrer esa senda - y elaborar la idea de poli(é)tica y sus imperativos - en apasionante y continuado diálogo con Javier Muguerza y su firme voluntad de ir más allá del contractualismo a través de esa filosofía del disenso que arranca de La razón sin esperanza y queda establecida en Desde la perplejidad. Ya en capítulo de deudas, no puedo dejar de reconocer la contraída en esta tarea con Fernando Quesada, por su estímulo intelectual de tantos años.

${ }^{22}$ Cf. «Legitimidad como hegemonía emancipadora (Hacia un enfoque ético-político de la legitimidad)», en J. M. González y C. Thiebaut (eds.), Convicciones políticas y responsabilidades éticas, Barcelona, Anthropos, 1990. Al contrario de lo ocurrido con la mayoría de sus intérpretes, el primer Rawls suscitó más reticencias en mí que el segundo (al margen de mi perenne admiración hacia $A$ Theory of Justice, por haber sido capaz de situar la cuestión de la justicia en el lugar que le correspondía): si abandono de la teoría economicista de la elección racional y su insistencia posterior en una concepción postmetafísica del filosofar político allanaron el camino de mi actual empatía, más allá de las diferencias que subsisten.

${ }^{23}$ Cf. «Identidad de la política (Una cartografía de las filosofías políticas tardomodernistas)», Laguna. Revista de Filosofia, 1, 1992, pp. 33-48. 